\title{
An assessment of factors affecting neurological recovery after spinal cord injury with vertebral fracture
}

\author{
P Bravo, C Labarta, MA Alcaraz, J Mendoza and A Verdú \\ Hospital Nacional de Parapléjicos, Complejo Hospitalario, Toledo, Spain
}

\begin{abstract}
In order to assess some of the variables associated with neurological recovery after traumatic spinal cord injury with vertebral fracture, a randomised sample of 100 patients (50 without neurological recovery, and 50 with several degrees of recovery) were selected out of 245 patients admitted to our hospital. Both groups were homogeneous with respect to time lapse to admission, hospitalization time and level of lesion. Of the variables considered, the intensity of the lesion (incomplete) and vertebral displacement (under 30\%) were statistically associated with neurological recovery. An age under 30 years at the moment of the injury was also associated with neurological recovery but only in those patients with an incomplete lesion. No correlation was found between the other variables studied such as the degree of vertebral wedging, type of fracture (compression, flexion-rotation) and management (conservative, surgical) and the neurological evolution.
\end{abstract}

Keywords: spinal cord injury; vertebral fracture; neurological recovery

\section{Introduction}

In an attempt to elucidate the factors, if any, associated with neurological improvement after a spinal cord lesion with vertebral fracture, we have made a retrospective study comparing patients who had an improvement in their functional and neurological status with patients who had no improvement. This approach may yield useful information for the management of patients as well as for their prognosis.

\section{Materials and methods}

From a total population of 245 patients admitted to the Hospital between January 1989 and September 1991, we have studied a randomized sample of 100 patients, of whom 50 showed neurological improvement, and 50 did not, according to Frankel's scale. Time lapse from injury to admission was less than 30 days in all of the patients.

The variables studied were: age; time elapsed from lesion to hospital admission; lesion level (cervical, thoracic and lumbar); type of lesion (complete, incomplete); type of fracture (compression, flexionrotation and hyperextension); Frankel score on admission and discharge; radiological features on admission (vertebral wedging, dislocation); and type of treatment (conservative, surgical). The type of fracture was classified according to Holdsworth. ${ }^{1}$ The neurological status was graded using the Frankel ${ }^{2}$ scoring system: $\mathrm{A}=$ complete lesion; $\mathrm{B}=$ complete motor and incomplete sensation; $\mathrm{C}=$ motor function

Correspondence: Dr P Bravo present but useless; $\mathrm{D}=$ motor function present and useful; $E=$ no neurological deficit. The percentage of vertebral wedging was defined as $(100-\mathrm{BA} / \mathrm{BP}) \times 100$, where $\mathrm{BA}$ and $\mathrm{BP}$ are, respectively, the height of the anterior and posterior aspects of the fractured vertebral body. The percentage of the degree of dislocation was defined as the distance of rear dislocation of the fractured vertebra divided by the normal width of the vertebra immediately below the fractured one; this value was then multiplied by 100 .

Conservative treatment employed for those with thoracic and lumbar fractures was based on postural measures for $6-8$ weeks, as described by Guttmann. ${ }^{3}$ Cervical fractures were treated by continuous traction with $6-8 \mathrm{~kg}$ weight for $6-8$ weeks, followed by a neck collar during 6-8 weeks. Within the group of patients subject to surgical treatment, vertebral fixation was performed in $84 \%$, whereas laminectomy with or without fixation was performed in $16 \%$.

The statistical study included the chi-square test, comparison of mean values (Student's $t$ test), analysis

Table 1 Frankel scale distribution of the patients at admission and discharge

\begin{tabular}{lccccc}
\hline & $A$ & $B$ & $C$ & $D$ & $E$ \\
\hline A & 40 & 4 & 2 & 11 & 1 \\
B & & 9 & 3 & 9 & \\
C & & & 1 & 20 & \\
D & & & & & \\
E & & & & & \\
\hline
\end{tabular}


of variance and multiple logistic regression; ${ }^{4} P$ values under 0.05 were considered statistically significant. Where appropriate, mean values are expressed as mean \pm standard error.

\section{Results}

A summary of the evolution of the neurological status of all of the patients studied is shown in Table 1. The time from injury to admission, the mean hospitalization time and the lesion level did not differ statistically with regards to neurological improvement (Table 2), showing that both groups of patients (with and without neurological improvement) were homogeneous with respect to these features. The following variables were not statistically different between the two groups: vertebral wedging, type of fracture and treatment modality (Table 3 ). The mean age of the group with improvement $(24.1 \pm 1$ years) was significantly lower than the mean age of those without improvement $(29.8 \pm 1.3$ years) with $P<0.01$. There was a significant association $(P<0.001)$ between the intensity of the lesion and the neurological evolution; patients with incomplete lesions showed a better neurological outcome (Table 4). Likewise, a percentage of vertebral displacement under $30 \%$ was significantly associated $(P<0.001)$ with neurological improvement (Table 4). Within the group of patients with complete lesions, there were no significant differences in the improvement rate with respect to age; however, in the group of patients with incomplete lesions, those who were aged

Table 2 Neurological evolution according to some of the features of the sample

\begin{tabular}{|c|c|c|c|}
\hline & Improvement & $\begin{array}{l}\text { Without } \\
\text { change }\end{array}$ & Significance \\
\hline $\begin{array}{l}\text { Time to } \\
\text { admission }^{\mathrm{a}}\end{array}$ & $9.2 \pm 8$ & $12.8 \pm 7$ & $P=0.17 \mathrm{NS}$ \\
\hline $\begin{array}{l}\text { Hospitalization } \\
\text { time }^{\mathrm{a}}\end{array}$ & $186 \pm 81$ & $216 \pm 74$ & $P=0.27 \mathrm{NS}$ \\
\hline \multicolumn{4}{|l|}{ Lesion Level } \\
\hline Cervical & 17 & 17 & \\
\hline Thoracic & 18 & 17 & $\chi^{2}[2]=0.06 \mathrm{NS}$ \\
\hline Lumbar & 15 & 16 & \\
\hline
\end{tabular}

${ }^{a}$ Mean \pm SE number of days less than 30 years did significantly better than those of older age (Table 5).

In order to control for possible confounding factors, a logistic multiple regression analysis of the neurological outcome was made with regard to the following variables: age, type of lesion, percentage of displacement, type of fracture, percentage of wedging and treatment. As shown in Table 6, only three variables (age, severity of lesion, vertebral displacement) were found to be correlated with neurological outcome.

\section{Discussion}

We have found that the degree of vertebral displacement, the severity of the spinal cord injury, and age

Table 3 Variables without statistical significance

\begin{tabular}{lccc} 
& Improvement & $\begin{array}{l}\text { Without } \\
\text { change }\end{array}$ & Significance \\
\hline $\begin{array}{l}\text { Treatment } \\
\quad \text { Conservative }\end{array}$ & 29 & 23 & \\
$\quad \begin{array}{l}\text { Surgical } \\
\text { Vertebral }\end{array}$ & 21 & 27 & $\chi^{2}[1]=1.4 \mathrm{NS}$ \\
$\quad$ wedging & & & \\
$\quad<30 \%$ & 29 & 28 & \\
$\quad>30 \%$ & 21 & 22 & $\chi^{2}[1]=0.04 \mathrm{NS}$ \\
$\begin{array}{l}\text { Type of fracture } \\
\quad \text { Compression }\end{array}$ & 15 & 12 & \\
$\quad \begin{array}{l}\text { Flexion- } \\
\quad \text { rotation }\end{array}$ & 34 & 38 & $\chi^{2}[1]=0.6 \mathrm{NS}$ \\
\hline
\end{tabular}

Table 4 Variables associated with neurological outcome

\begin{tabular}{lccc} 
& $\begin{array}{c}\text { Improve- } \\
\text { ment }\end{array}$ & $\begin{array}{c}\text { Without } \\
\text { change }\end{array}$ & Significance \\
\cline { 2 - 3 } Spinal injury & & & \\
$\quad$ Incomplete & 32 & 10 & \\
$\quad$ Complete & 18 & 40 & $\chi^{2}[1]=18, P<0.001$ \\
Vertebral & & & \\
$\quad$ displacement & & & \\
$\quad<30 \%$ & 45 & 23 & \\
$>30 \%$ & 5 & 27 & $\chi^{2}[1]=22, P<0.001$ \\
\hline
\end{tabular}

Table 5 Neurological outcome according to age and intensity of injury

\begin{tabular}{lcccc}
\hline & Improvement & Without change & Significance & Odds ratio \\
\hline $\begin{array}{c}\text { Complete } \\
<30 \text { years }\end{array}$ & 13 & 26 & & \\
$\quad>30$ years & 5 & 14 & $\chi^{2}[1]=0.29 \mathrm{NS}$ & $1.3(0.33-5.6)$ \\
Incomplete & 26 & 2 & & \\
$\quad<30$ years & 6 & 8 & $\chi^{2}[1]=12, P<0.001$ & $17(2.4-162)$ \\
$>30$ years & & & & \\
\hline
\end{tabular}


Table 6 Multiple logistic regression analysis of neurological outcome in relation to intensity of lesion, age, percentages of vertebral displacement and wedging, type of fracture and treatment

\begin{tabular}{|c|c|c|c|c|c|}
\hline & Regr. Coef: & Strd. Err. & $T$ & Probability & \\
\hline Neurological outcome & -6.2568 & 1.5873 & 3.9417 & 0.00016 & \\
\hline Intensity of lesion & 2.5156 & 0.6931 & 3.6295 & 0.00055 & \\
\hline Age & 0.12989 & 0.037732 & 3.4425 & 0.0008764 & \\
\hline Vertebral displacement & 1.7528 & 0.69036 & 2.539 & 0.013 & \\
\hline Vertebral wedging & 0.3342 & 0.59947 & 0.55749 & 0.058 & NS \\
\hline Type of fracture & 1.3415 & 0.69834 & 1.9209 & 0.057 & NS \\
\hline Treatment & -0.12112 & 0.60094 & 0.20155 & 0.84 & NS \\
\hline
\end{tabular}

can be considered factors influencing the neurological evolution after spinal cord trauma with fracture. We have not found that other aspects such as the type of fracture, the degree of vertebral wedging or the treatment modality have a significant influence on the outcome.

In our study, as well as in those of other workers, ${ }^{2,5-9}$ patients with incomplete lesions have shown a significantly better neurological outcome than patients with complete neurological lesions. Thus, much evidence seems to indicate that a complete lesion can be considered to be associated with a lack of neurological improvement. Likewise, vertebral displacement above $30 \%$ appears to be another factor associated with a poor neurological prognosis. For this reason, we advocate early reduction of fracturedislocations, as has also been recommended by Harris et al. ${ }^{10}$ Age has been found to be a factor only in patients with incomplete neurological lesions, in such a way that patients who were over 30 years of age had a significantly worse rate of improvement.

According to our data, the neurological outcome is not related to the type of treatment, be it conservative or surgical. The postulated reasons that justify many surgical interventions are based mainly on the hope that early surgical reduction and stabilization will eventually lead to some degreee of improvement in neurological function. Other reasons include the prevention of possible late vertebral displacement, the mitigation of pain due to kyphosis, and the shortening of hospitalization time. ${ }^{11}$ However, there is no definitive evidence showing that early surgical procedures enhance neurological recovery. This may be mainly because non-reversible neurological damage occurs just at the moment of the initial trauma. ${ }^{1}$ Furthermore, some reports have shown no differences between different surgical strategies. ${ }^{12,13}$ Undoubtedly patients who receive surgical treatment can get out of bed sooner than those treated conservatively, but surgery does carry certain risks. ${ }^{14}$ For these reasons it is our opinion that the strategy of management should be planned by the different specialists involved in the specialised spinal cord injury units, not only by orthopaedic surgeons. ${ }^{9,15,16}$

\section{References}

1 Holdsworth FW. Fractures, dislocations and fractures-dislocations of the spine. J Bone Joint Surg 1963; 45B: 6-20.

2 Frankel HL, Hancock DO, Hislop G, Melzak J, Michaelis LS, Ungar GH et al. The value of postural reduction in the initial manafement of closed injuries of the spine with paraplegia and tetraplegia. Part I. Paraplegia 1969; 7: 179-192.

3 Guttmann L. Tratamiento de las fracturas de la columna. Lesiones Medulares. Tratamiento Global e Investigación. 1981; Jims, Barcelona: $141-180$.

4 Schlesselman JJ. Case-Control Studies. 1982; Oxford University Press, New York: 194-206.

5 Burke DC, Murray DD. The management of thoracic and thoracolumbar injuries of the spine with neurological involvement. J Bone Joint Surg 1976; 58B: $72-78$.

6 Davies WE, Morris JJ, Hill V. An analysis of conservative (non surgical) management of thoracolumbar fractures and fracturedislocations with neuronal damage. J Bone Joint Surg 1980; 62A: $1324-1328$

7 Biering-Sorensen F, Pedersen V, Clausen S. Epidemiology of spinal cord lesions in Denmark. Paraplegia 1990; 28: 105-118.

8 Dickson JH, Harrington PR, Erwin WD. Results of reduction and stabilization of the severely fractured thoracic and lumbar spine. J Bone Joint Surg 1978; 60A: 799-805.

9 Young JS, Dexter WR. Neurological recovery distal to the zone of injury in 172 cases of close traumatic spinal cord injury. Paraplegia 1978; 16: $39-49$.

10 Harris P, Karmi MZ, McClemont E, Matlhoko D, Paul S. The prognosis of patients sustaining severe cervical spine injury (C2C7 inclusive). Paraplegia 1980; 18: $324-330$.

11 Dickson RA. Spinal injuries: early surgical treatment. Paraplegia 1992; 30: $43-45$.

12 Carl-Axel C, Pelletieri L. Treatment of spinal cord injuries in the thoracolumbar region. Scand J Rehab Med 1987; 19: 71 - 75 .

13 Osebold WR, Weinstein SL, Sprague BL. Thoracolumbar spine fractures. Results of treatment. Spine 1981; 6: 13-34.

14 Bravo P, Labarta C, Alcaraz MA, Mendoza J, Verdú A. Outcome after vertebral fractures with neurological lesion treated either surgically or conservatively in Spain. Paraplegia 1993; 31: 358 366.

15 Brown DJ. Spinal cord injuries: the last decade and the next. Paraplegia 1992; 30: $77-82$.

16 Bedbrook GM. Spinal injuries with tetraplegia and paraplegia. $J$ Bone Joint Surg 1979; 61B: 267-284. 